\title{
Pain and Schizophrenia: About Two Clinical Cases
}

\author{
F. Laboudi, MD, Phd ${ }^{1,3}$, A.Ouanass $\mathrm{MD}^{2,3}$ \\ ${ }^{1}$ Psychiatry Department, Ouarzazate, Morocco \\ ${ }^{2}$ Psychiatric Emergency Department, University Hospital psychiatric Ar-razi,Salé \\ ${ }^{3}$ Faculty of Medicine and Pharmacy, Mohammed V University, Rabat, Morocco
}

\begin{abstract}
Pain is a complex sensation influenced by many psychological, relational and socialfactors. Perception and / or painful expression may be wrong in the case of certain chronic diseases such as schizophrenia. In this work we report the cases of two patients with schizophrenia who presented during their hospitalization, abnormal reactivity to pain, to better approach the sensitivity to pain during psychiatric illness. The pain of the schizophrenic patient is too often underestimated, undervalued and under-treated while it is part of everyday life. The responses of a schizophrenic patient during a medical examination with pain research must be taken seriously. Clinicians should maintain a high degree of suspicion of serious illness in the evaluation of these patients.
\end{abstract}

Keywords: Pain, Schizophrenia, Perception, reactivity to pain, Hypoalgesia

\section{Introduction}

Pain is a complex sensation influenced by many psychological, relational and social factors. Perception and / or painful expression may be wrong in the case of certain chronic diseases such as schizophrenia is a complex psychiatric disorder with an incidence of about 0.20 / 1000 / year [1]. It is characterized by a heterogeneous clinical expression [2]. Clinical observations report that some patients with schizophrenia have a decreased perception of pain while others have decreased expression [3], but the objective evidence is rare [4]. There is no consent on the relevant thereby mechanism. This frequently leads to difficulties in diagnosis emergencies. What makes difficult the management of pain in these patients with schizophrenia who are sometimes neglected. The pain of the schizophrenic patient is too often underestimated, undervalued and undertreated while it is part of everyday life. Better understandings of Algonkian phenomenon in patients with schizophrenia have a positive impact on medical care.

In this work we report the cases of two patients with schizophrenia who presented during their hospitalization, abnormal reactivity to pain, to better approach the sensitivity to pain during psychiatric illness.

\section{Clinical Case 1:}

Mr. A.A aged 25 was hospitalized in our department as part of a symptomatic reactivation of his schizophrenia evolving for several years, following a therapeutic range and that is stabilized in $15 \mathrm{mg}$ haloperidol and chlorpromazine 200mg / day.

During his hospital stay,the patient hit his left foot to the wall in a frame impulsive after a dispute with another patient. His left foot is inflamed with swelling, redness and local heat.

The patient arrives at the emergency trauma by stepping on the foot that turned out he broke no complain of any pain. This fracture has necessitated the establishment of a cast boot. But the patient is normally included, leaning on his boot and refused to boot at the hospital, which required continuous monitoring by nursing staff.

\section{Clinical Case 2:}

Mr. LM 17 years old was hospitalized urgently to attempt suicide by defenestration in a hallucinatory framework, following which he had several fractures in the hands and feet, who needs several surgeries, with analgesic treatment and anti-inflammatory. It got to the service without crutches. He never followed the instructions of the trauma. He walked without expressing any pain. This required the use of restraints for several days until a good improvement.

\section{Discussion}

The word schizophrenia (Greek or Skhizein, meaning split, and or phren, meaning spirit) was given by EugenBleuler in 1911. Shortly afterthe original description of schizophrenia established by Emil Kraepelin. It is characterized by heterogeneity of Clinque table. The symptoms of schizophrenia fall into three main dimensions: positive (hallucinations and delusions), negative (abulia, apathy and social withdrawal) and disorganized (abnormal thinking, inconsistency and ambivalence shares) usually associated with neurocognitive deficits.

Decreased pain sensitivity in schizophrenia still subject to controversy, has been reported for over a century with the work of Kraepelin and Bleuler [5]. The works that were interested in the perception of pain in schizophrenia are numerous and they are produced and mixed.

The patients with schizophrenia have an increased tolerance to painful stimuli. In fact, increased pain threshold was observed even since the first descriptions of the disease, indeed Kraepelin reported adaptive withdrawal reaction to different types of injuries such as burns or needle spikes [6].

In the above clinical cases, are patients with severe somatic injury or pain are a warning means, normally forcing the subject to ask for help, and to put to rest with his body. 


\section{International Journal of Science and Research (IJSR) \\ ISSN (Online): 2319-7064}

Index Copernicus Value (2013): 6.14 | Impact Factor (2015): 6.391

The absence of these reactions in these patients has complicated their decision in somatic load, which can cause serious complications.

Several hypotheses have been proposed to explain these changes in pain sensitivity in schizophrenia, which are grouped into five main themes [7] where the perception of pain is influenced by:

1) negative symptoms,

2) positive symptoms,

3) cognitive symptoms,

4) and motor symptoms

5) mood symptoms.

\section{Hypoalgesia schizophrenic}

Guieu already and all in 1994, found that pain thresholds of patients with schizophrenia often appear different from those of healthy subjects. Indeed he evaluated pain thresholds ten schizophrenia patients and ten controls by measuring the bending nociceptive leg reflex threshold: the stimulationthreshold, at which this reflex is triggered, is known to be correlated with pain threshold, to arrive at the conclusion that in most cases, increasing the pain threshold is the result of "attitude" and no alterations in brain function [8].

the observations of caregivers, yielding a hypo sensitivity of schizophrenic patients (Blumensohn and al., 2002) [9]. Jochum et al. (2006) studied patients with schizophrenia and identifies thresholds and tolerance to thermal pain and demonstrate that the differences in the perception of pain can be attributed to information processing abnormalities in schizophrenia [10].

A literature review conducted by Bonnotand al. (2009) reported that in most situations responsiveness to behavioral pain responses and self-reported pain are reduced in schizophrenia [11].

However, there is little or no physiological evidence supporting insensitivity to pain in schizophrenia. One can suggest that the widely accepted notion of reduced sensitivity to pain in schizophrenia is related more to a different mode of expression of pain from that of a real endogenous analgesia.

In Potvin analysis suggests that all patients with schizophrenia show a decreased response to pain. Secondary analyzes showed that: the sensory thresholds are increased in patients with schizophrenia. This meta-analysis supports the hypothesis of a reduced pain response in schizophrenia. The study also suggests that hypoalgesia in schizophrenia cannot be explained solely by the effects of antipsychotic drugs, and it may not be a specific response to blunt the pain. Goffauxand al. in 2007 estimated that changes in pain produced by psychological factors are expected to result from the activity of specific cortical areas. However, subcortical nuclei, including the periaqueductal gray and medulla, also show a selective activation when subjects expect pain relief. These regions of the brainstem send inhibitory projections to the backbone and produce diffuse analgesic responses. Unfortunately, the precise contribution of the mechanisms of the spine in the prediction of the strength of the unknown placebo analgesia[12].

\section{Effect of Clinical Signs}

Significant fluctuations felt schizophrenic patients is observed. Potvin and Marchand (2008) suggests that hypoalgesia in schizophrenia cannot be explained solely by the effects of antipsychotic drugs, and it may not be a specific response to blunt the pain.

However, other authors suggest that patients have a pain sensitivity that is identical to that of healthy subjects. The apparent analgesia is the result of an "attitude" of refusal, a different way of expressing the pain related to the difficulties of non-verbal communication, not an impairment of brain function or a biological abnormality [13]. The clinician must pay more attention to the expression of pain expressed in language and behavior visibly different from those normally used

\section{Conclusion}

The pain remains at the center of care by its call value, diagnosis and need for treatment. The pain of the schizophrenic patient is too often underestimated, undervalued and under-treated while it is part of everyday life. The responses of a schizophrenic patient during a medical examination with pain research must be taken seriously although research on the cause of pain perception in psychotic patients changed continues; clinicians should maintain a high degree of suspicion of serious illness in the evaluation of these patients [14]. The study of pain has to look at other psychiatric disorders such as depression, addictions and personality disorders.

\section{Ethics approval and consent to participate: Not applicable in this section}

Consent for publication: the authors have consent from the patient to publish

\section{No Competing Interests}

\section{Authors' Contributions}

All the authors have contributed to the manuscript (surgery, scientific research..

\section{References}

[1] Messias E, Chen C-Y, William W. Eaton, Epidemiology of Schizophrenia: Review of Findings and Myths, Psychiatr Clin North Am. 2007 Sep; 30(3): 323-338.

[2] Franck N, Clinique de la schizophrénie, EMCPsychiatrie, Volume 10, n॰ 1, janvier 2013

[3] Bickerstaff LK, Harris SC, Leggett RS, Cheah KC., Pain insensitivity in schizophrenic patients. A surgical dilemma., Arch Surg. 1988 Jan;123(1):49-51.

[4] Duval CZ, Goumon Y, Kemmel V, Neurophysiological responses to unpleasant stimuli (acute electrical stimulations and emotional pictures)

\section{Volume 5 Issue 6, June 2016 www.ijsr.net}




\section{International Journal of Science and Research (IJSR) \\ ISSN (Online): 2319-7064}

Index Copernicus Value (2013): 6.14 | Impact Factor (2015): 6.391

are increased in patients with schizophrenia, Sci Rep. 2016 Mar 3;6:22542.

[5] Potvin S, Marchand S., Hypoalgesia in schizophrenia is independent of antipsychotic drugs: a systematic quantitative review of experimental studies., Pain. 2008 Aug 15;138(1):70-8.

[6] Iulia Antioch, Alin Ciobica, Manuel Paulet, Veronica Bild, Radu Lefter \& Daniel Timofte: Pain manifestations in schizophrenia - clinical and experimental aspects in human patients and animal models Psychiatria Danubina, 2015; Vol. 27, No. 2, pp 142-152

[7] Lévesque, Mylène, Perception de la douleur dans la schizophrénie : mécanismes excitateurs de la douleur, Université Sherbrooke, Québec, Canada, mai, 2012

[8] Guieu R, Samuélian JC, Coulouvrat H., Objective evaluation of pain perception in patients with schizophrenia., Br J Psychiatry. 1994 Feb;164(2):2535.

[9] Blumensohn R, Ringler D, Eli I., Pain perception in patients with schizophrenia. J Nerv Ment Dis. 2002 Jul;190(7):481-3.

[10] Jochum T, Letzsch A, Greiner W, Wagner G, Sauer H, Bär KJ. Influence of antipsychotic medication on pain perception in schizophrenia. Psychiatry Res. 2006 Jun 15;142(2-3):151-6. Epub 2006 Apr 24.

[11] Bonnot O, Anderson GM, Cohen D, Willer JC, Tordjman S. Are patients with schizophrenia insensitive to pain? A reconsideration of the question. Clin J Pain. 2009 Mar-Apr;25(3):244-52

[12] Goffaux P, Redmond WJ, Rainville P, Marchand S., Descending analgesia--when the spine echoes what the brain expects., Pain. 2007 Jul;130(1-2):137-43

[13] Autié A, Montreuil M, Moulier V, Braha S, Wojakiewicz A, Januel D, Douleur et schizophrénie : mythe et réalité, L'Encéphale, Vol 35 - N 4, P. 297303 - septembre 2009

[14] Rosenthal SH, Porter KA, Coffey B., Pain insensitivity in schizophrenia. Case report and review of the literature, Gen Hosp Psychiatry. 1990 Sep;12(5):31922. 